\title{
The IMPACT Study - Single Inhaler Triple Therapy (FF/UMEC/VI) Versus FF/VI And UMEC/VI In Patients With COPD: Efficacy And Safety In A Japanese Population
}

This article was published in the following Dove Press journal:

International Journal of Chronic Obstructive Pulmonary Disease

\section{Motokazu Kato (iD) \\ Keisuke Tomii (iD ${ }^{2}$ \\ Kenichi Hashimoto ${ }^{3}$ \\ Yasuko $\mathrm{Nezu}^{3}$ \\ Takeo Ishii ${ }^{4}$ \\ C Elaine Jones ${ }^{5}$ \\ Sally Kilbride ${ }^{6}$ \\ Annette S Gross ${ }^{7}$ \\ Christine S Clifton ${ }^{7}$ \\ David A Lipson (1D) 8,9 \\ 'Chest Disease Clinical and Research Institute, Kishiwada City Hospital, Kishiwada, Japan; ${ }^{2}$ Department of Respiratory Medicine, Kobe City Medical Center General Hospital, Kobe, Japan; \\ ${ }^{3}$ Evidence Generation Department, GlaxoSmithKline K.K., Tokyo, Japan; ${ }^{4}$ MA Respiratory Department, GlaxoSmithKline K.K., Tokyo, Japan; ${ }^{5}$ Development, R\&D, GlaxoSmithKline, Research Triangle Park, NC, USA; ${ }^{6}$ Biostatistics, GlaxoSmithKline, Uxbridge, Middlesex, UK; ${ }^{7}$ Clinical Pharmacology Modelling \& Simulation, GlaxoSmithKline R\&D, Sydney, Australia; ${ }^{8}$ Clinical Sciences, GlaxoSmithKline, Collegeville, PA, USA; ${ }^{\text {Pulmonary, Allergy }}$ and Critical Care Division, Department of Medicine, Perelman School of Medicine, University of Pennsylvania, Philadelphia, PA, USA}

Correspondence: Yasuko Nezu Evidence Generation Department, Respiratory Medical Affairs \& Development GlaxoSmithKline K.K., Akasaka Intercity AIR I-8-I Akasaka, Minato-Ku, Tokyo 107-0052, Japan

Tel +8I 3 423I 5064

Fax +8I 3 423I 5994

Email yasuko.2.nezu@gsk.com
Purpose: The Informing the Pathway of COPD Treatment (IMPACT) study demonstrated that single-inhaler triple therapy fluticasone furoate/umeclidinium/vilanterol (FF/UMEC/VI) reduces moderate/severe exacerbation rates and improves lung function and health status versus FF/VI or UMEC/VI dual therapy in patients with symptomatic COPD and a history of exacerbations. This analysis evaluated the efficacy and safety of FF/UMEC/VI in patients enrolled in Japan.

Patients and methods: IMPACT was a 52-week, randomized, double-blind, multicenter study comparing FF/UMEC/VI 100/62.5/25 $\mu \mathrm{g}$ with FF/VI 100/25 $\mu \mathrm{g}$ or UMEC/VI 62.5/25 $\mu \mathrm{g}$ in patients $\geq 40$ years with symptomatic COPD and $\geq 1$ moderate/severe exacerbation in the previous year. Endpoints included annual rate of on-treatment moderate/severe exacerbations (primary endpoint), time-to-first on-treatment moderate/severe exacerbation and change from baseline at Week 52 in trough $\mathrm{FEV}_{1}$, post-bronchodilator $\mathrm{FEV}_{1}$, St. George's Respiratory Questionnaire, and COPD Assessment Test score. Safety was also assessed. Results: The Japan subgroup accounted for only 4\% (378/10,355) of the overall IMPACT intent-to-treat (ITT) population. In the Japan subgroup, FF/UMEC/VI reduced the annual rate of on-treatment moderate/severe exacerbations by $15 \%(95 \% \mathrm{CI}:-20,40)$ versus $\mathrm{FF} / \mathrm{VI}$ (compared with $15 \%[10,20]$ in the ITT) and $36 \%$ (95\% CI: 6, 57) versus UMEC/VI (compared with $25 \%[19,30]$ in the ITT). FF/UMEC/VI reduced moderate/severe exacerbation risk (time-to-first), improved lung function and health status at Week 52 versus both dual therapies. These results were in the same direction and of a generally similar magnitude to those seen in the overall ITT population. No new safety signals were identified in the Japan subgroup compared with the ITT population. Pneumonia incidence was higher with $\mathrm{FF} / \mathrm{UMEC} / \mathrm{VI}$ and FF/VI versus UMEC/VI.

Conclusion: These results highlight the favorable benefit-risk profile of FF/UMEC/VI single-inhaler triple therapy compared with FF/VI or UMEC/VI dual therapy in patients in Japan with symptomatic COPD and $\geq 1$ exacerbation in the prior year.

Keywords: triple therapy, fluticasone furoate, Japan, umeclidinium, vilanterol, COPD exacerbation

\section{Introduction}

COPD is characterized by persistent respiratory symptoms, including dyspnea, cough, sputum production, and a history of recurrent lower respiratory tract infections, and airflow limitation. ${ }^{1}$ COPD is a leading cause of morbidity and mortality globally and is 
projected to be the fourth leading cause of death by $2040 .^{2-4}$ Key differences exist in the pattern of COPD between Western and Asian countries, with COPD being associated with a higher burden in Asian countries in terms of years spent living with disability and years of life lost. $^{5}$ Furthermore, patients in Asia, including Japan, have been shown to experience fewer, but more severe, exacerbations compared with other countries. ${ }^{6,7}$ In Japan, the prevalence of COPD is similar to that in other industrialized economies ${ }^{8}$ and COPD is an important driver of impaired health-related quality of life (HRQoL) and productivity loss, resulting in significant socioeconomic burden. ${ }^{6}$ Compared with patients with COPD in other countries, patients in Japan are more likely to be male, older, and have a lower body mass index (BMI). ${ }^{9}$ They also tend to underreport their symptoms and exacerbations. ${ }^{10}$

The Japanese Respiratory Society guidelines and the GOLD report both recommend an individualized and stepwise approach to the pharmacological management of COPD, with treatment recommendations based on a comprehensive assessment of the patient's condition and guided by symptom severity and risk of exacerbations. ${ }^{1,11}$ However, there are differences in recommended COPD management between these documents and therefore further evidence is needed to support the management of patients with COPD in Japan. The GOLD report recommends treatment initiation based on symptoms and risk of exacerbations, and treatment escalation based on the persistence of dyspnea and exacerbation recurrence. ${ }^{1}$ Triple therapy with an inhaled corticosteroid (ICS), a long-acting muscarinic antagonist (LAMA), and a long-acting $\beta_{2}$-agonist (LABA) is recommended for patients with clinically significant symptoms or recurrent exacerbations on dual LAMA/LABA or ICS/LABA therapy. ${ }^{1}$ The Japanese guidelines include a stepwise approach for patients with COPD of any severity. ${ }^{11}$ The 2013 guidelines recommended escalation to dual therapy in patients for whom mono-bronchodilator therapy failed to provide sufficient benefits, and addition of ICS to LAMA and/or LABA therapy in patients experiencing repeated exacerbation. ${ }^{12}$ In contrast, the most recent guidelines recommend the addition of ICS to mono- or dual bronchodilator therapy for patients with COPD with asthmatic features, ${ }^{11}$ which also contrasts with the GOLD recommendations, where the addition of ICS to bronchodilator therapy is guided by a patient's exacerbation control on therapy. ${ }^{1}$

The Informing the Pathway of COPD Treatment (IMPACT) trial evaluated single-inhaler ICS/LAMA/LABA triple therapy with fluticasone furoate $(\mathrm{FF}) /$ umeclidinium
(UMEC)/vilanterol (VI) versus dual therapy with FF/VI (ICS/LABA) or UMEC/VI (LAMA/LABA) in patients $\geq 40$ years of age with symptomatic COPD and $\geq 1$ moderate/severe exacerbation in the previous year. ${ }^{13} \mathrm{FF} / \mathrm{UMEC} / \mathrm{VI}$ triple therapy resulted in a significantly lower rate of moderate/severe exacerbations, alongside improvements in lung function and health status, compared with FF/VI or UMEC/VI, with a similar safety profile between treatments. ${ }^{13}$ The IMPACT study was conducted in 37 countries and analyses by geographic region were conducted to investigate potential differences from the intent-to-treat (ITT) population.

In order to provide further evidence to inform the management of patients with COPD in Japan, an analysis of data from the subgroup of patients from the IMPACT study who were enrolled in Japan was undertaken to evaluate the efficacy and safety of FF/UMEC/VI relative to dual therapy with FF/VI or UMEC/VI in this subgroup. Data from the overall study population are also presented to provide context. The FF/VI and UMEC/VI doses used in the IMPACT study are those approved in Japan, which are the same as those used globally. ${ }^{14-17}$

\section{Methods \\ Study Design}

The IMPACT study (study CTT116855, NCT02164513) was a Phase III, multicenter, randomized, double-blind, parallel-group study conducted in 37 countries between June 2014 and July 2017, the design of which has been described previously. ${ }^{13,18}$ Briefly, patients continued their existing COPD maintenance therapy during a 2-week runin period prior to being randomized $(2: 2: 1)$ to receive triple therapy FF/UMEC/VI 100/62.5/25 $\mu \mathrm{g}$, or dual therapy with FF/VI 100/25 $\mu \mathrm{g}$, or UMEC/VI $62.5 / 25 \mu \mathrm{g}$ for 52 weeks, all administered once daily via the Ellipta dry powder inhaler. ${ }^{13,18}$ Rescue medication (salbutamol) was available on an as-needed basis throughout the study.

\section{Study Population}

Eligibility criteria have been reported previously. ${ }^{13,18}$ Patients were $\geq 40$ years of age with symptomatic COPD (COPD Assessment Test [CAT] score $\geq 10$; COPD defined by the American Thoracic Society/ European Respiratory Society ${ }^{19}$ ); current or former smokers (smoking history $\geq 10$ pack-years); and either had a post-bronchodilator $\mathrm{FEV}_{1}<50 \%$ predicted and a history of $\geq 1$ moderate/severe exacerbation, or a post-bronchodilator $50 \% \leq \mathrm{FEV}_{1}<80 \%$ predicted, and $\geq 2$ moderate or 
$\geq 1$ severe exacerbation in the previous 12 months. Participants were excluded if they had a concomitant diagnosis of asthma or other respiratory disorders, and pneumonia or other respiratory tract infections not resolved $\leq 14$ days or $\leq 7$ days prior to screening, respectively. A prior history of asthma, common in patients with COPD ${ }^{20}$ was not an exclusion criterion; however, the patient's symptoms were required to be primarily due to COPD. This is consistent with other studies of triple therapy in $\mathrm{COPD}^{21,22}$ and improves the generalizability of results.

The ITT population included all randomized patients, excluding those who were randomized in error (ie, those who were screen failures and had not taken randomized medication). The Japan subgroup was derived from the ITT population and only included those patients enrolled in Japan. A list of participating study sites in Japan is available in the Supplementary material.

\section{Study Endpoints}

The study endpoints have been described previously. ${ }^{13,18}$ The prespecified analysis of IMPACT data for the subgroup of patients enrolled in Japan evaluated the following efficacy endpoints: the annual rate of on-treatment moderate/severe exacerbations (primary endpoint); time-to-first on-treatment moderate/severe exacerbation; change from baseline in trough $\mathrm{FEV}_{1}$ and post-bronchodilator $\mathrm{FEV}_{1}$ at Week 52; change from baseline in St. George's Respiratory Questionnaire (SGRQ) total score and CAT score at Week 52.

Moderate exacerbations were defined as events requiring treatment with oral/systemic corticosteroids and/or antibiotics, and severe exacerbations were defined as events that required hospitalization or resulted in death.

Safety endpoints included: incidence of adverse events (AEs), drug-related AEs; serious AEs (SAEs) and deaths, AEs of special interest (AESIs), and major adverse cardiovascular events (MACE). AESIs are AEs which have specified areas of interest for FF, UMEC, or VI, or for patients with COPD and allow for a comprehensive review of safety data that is not limited to a specific preferred term. Adjudication of serious adverse reports was performed by an independent adjudication committee who were asked to determine the primary cause of the report.

\section{Statistical Analyses}

Details of sample size calculations for the overall ITT population have been previously described. ${ }^{18}$ The study was not powered to demonstrate statistical significance for any endpoint in the Japan subgroup and all summaries and analyses for this cohort are for descriptive purposes only. No multiplicity adjustment was applied to the analyses of these data.

In the ITT population, the primary endpoint of annual rate of on-treatment moderate/severe exacerbation was analyzed using a generalized linear model assuming a negative binomial distribution and covariates of treatment group, sex, exacerbation history ( $\leq 1, \geq 2$ moderate/severe), smoking status (screening), geographical region, postbronchodilator percent predicted $\mathrm{FEV}_{1}$ (screening). For the Japan/Not Japan subgroup analyses, geographical region was removed as a covariate and replaced with the Japan/Not Japan covariate with an additional treatment group by Japan/Not Japan subgroup interaction term. Time-to-first on-treatment moderate/severe exacerbation was analyzed using a Cox proportional hazards model with the same covariates as for the analysis of exacerbation rates.

Change from baseline in trough and post-bronchodilator $\mathrm{FEV}_{1}$, SGRQ total score, and CAT score were analyzed in the ITT population using a repeated measures model with covariates of treatment group, smoking status (screening), geographical region, visit, baseline, baseline by visit, and treatment group by visit. For the Japan/Not Japan subgroup analyses, geographical region was removed as a covariate and replaced with the Japan/Not Japan covariate with additional treatment group by Japan/ Not Japan subgroup, visit by Japan/Not Japan subgroup and treatment group by visit by Japan/Not Japan subgroup interaction terms. Safety was summarized descriptively. All data (Japan/Not Japan) were included in the analyses described; however, only the Japan results are reported here.

\section{Results}

\section{Study Population}

A total of 10,355 patients were randomized in the ITT population, ${ }^{13}$ of which only $378(4 \%)$ were enrolled in Japan (FF/UMEC/VI: n=149; FF/VI: 149; UMEC/VI: 80). All patients enrolled in Japan were of Japanese ancestry. Patients enrolled in the ITT population were primarily of White ethnicity, as described previously. ${ }^{13}$ Of those treated, $304(80 \%)$ in the Japan cohort completed study treatment and $333(88 \%)$ completed the study, compared with 7991 (77\%) and 9087 (88\%), respectively, in the overall ITT population. 
Demographics and baseline characteristics by treatment arm are shown in Table 1 and were generally similar across the treatment groups in the Japan subgroup. As expected, some demographic characteristics in the Japan subgroup differed from the overall ITT population (Table 1). When compared with the overall ITT population, a higher

Table I Patient Demographics And Baseline Characteristics In The Japan Subgroup And Overall Study Population (ITT population)

\begin{tabular}{|c|c|c|c|c|c|c|}
\hline \multirow[t]{2}{*}{ Characteristic } & \multicolumn{3}{|l|}{ Japan } & \multicolumn{3}{|l|}{ Overall } \\
\hline & $\begin{array}{l}\text { FF/UMEC/VI } \\
n=149\end{array}$ & $\begin{array}{l}F F / V I \\
n=149\end{array}$ & $\begin{array}{l}\text { UMEC/VI } \\
n=80\end{array}$ & $\begin{array}{l}\text { FF/UMEC/ I } \\
n=4|5|\end{array}$ & $\begin{array}{l}F F / V I \\
n=4 \mid 34\end{array}$ & $\begin{array}{l}\text { UMEC/VI } \\
n=2070\end{array}$ \\
\hline Male, n (\%) & $139(93)$ & $140(94)$ & $72(90)$ & $2766(67)$ & $2748(66)$ & $1356(66)$ \\
\hline $\begin{array}{l}\text { Age, years, mean (SD) } \\
<65 \text { years, } \mathrm{n}(\%) \\
\geq 65 \text { years, } \mathrm{n}(\%)\end{array}$ & $\begin{array}{l}70.7(7.3) \\
22(15) \\
127(85)\end{array}$ & $\begin{array}{l}70.1(7.2) \\
32(21) \\
117(79)\end{array}$ & $\begin{array}{l}71.1(6.8) \\
14(18) \\
66(83)\end{array}$ & $\begin{array}{l}65.3(8.2) \\
1886(45) \\
2265(55)\end{array}$ & $\begin{array}{l}65.3(8.3) \\
1876(45) \\
2258(55)\end{array}$ & $\begin{array}{l}65.2(8.3) \\
962(46) \\
1108(54)\end{array}$ \\
\hline $\begin{array}{l}\text { BMI, } \mathbf{k g} / \mathrm{m}^{2}, \text { mean (SD) } \\
\leq 21 \mathrm{~kg} / \mathrm{m}^{2}, \mathrm{n}(\%) \\
<25 \mathrm{~kg} / \mathrm{m}^{2}, \mathrm{n}(\%)\end{array}$ & $\begin{array}{l}21.6(3.3) \\
63(42) \\
128(86)\end{array}$ & $\begin{array}{l}22.2(3.4) \\
57(38) \\
114(77)\end{array}$ & $\begin{array}{l}22.8(3.7) \\
26(33) \\
61(76)\end{array}$ & $\begin{array}{l}26.6(6.2) \\
739(18) \\
1856(45)\end{array}$ & $\begin{array}{l}26.7(6.1) \\
697(17) \\
1768(43)\end{array}$ & $\begin{array}{l}26.6(5.9) \\
340(16) \\
902(44)\end{array}$ \\
\hline $\begin{array}{l}\text { Smoking status, } \mathbf{n}(\%) \\
\text { Current smoker } \\
\text { Former smoker }\end{array}$ & $\begin{array}{l}40(27) \\
109(73)\end{array}$ & $\begin{array}{l}37(25) \\
112(75)\end{array}$ & $\begin{array}{l}14(18) \\
66(83)\end{array}$ & $\begin{array}{l}1436(35) \\
2715(65)\end{array}$ & $\begin{array}{l}\mid 423(34) \\
27||(66)\end{array}$ & $\begin{array}{l}728(35) \\
1342(65)\end{array}$ \\
\hline $\begin{array}{l}\text { Moderate/severe COPD exacerbations in } \\
\text { previous } \mathbf{2} 2 \text { months, } \mathbf{n}(\%) \\
<2 \text { moderate and } 0 \text { severe } \\
\geq 2 \text { moderate or } \geq 1 \text { severe }\end{array}$ & $\begin{array}{l}37(25) \\
112(75)\end{array}$ & $\begin{array}{l}41(28) \\
108(72)\end{array}$ & $\begin{array}{l}20(25) \\
60(75)\end{array}$ & $\begin{array}{l}1198(29) \\
2953(71)\end{array}$ & $\begin{array}{l}1242(30) \\
2892(70)\end{array}$ & $\begin{array}{l}616(30) \\
1454(70)\end{array}$ \\
\hline $\begin{array}{l}\text { Reversible to salbutamol, }{ }^{\mathrm{a}} \mathrm{n}(\%) \\
\text { Post-bronchodilator } \mathrm{FEV}_{1}, \% \text { predicted normal, mean } \\
\text { (SD) } \\
\text { Post-bronchodilator } \mathrm{FEV}_{1}, \mathrm{~L} \text {, mean (SD) } \\
\text { Pre-bronchodilator } \mathrm{FEV}_{1}, \% \text { predicted normal, mean } \\
\text { (SD) } \\
\text { Pre-bronchodilator } \mathrm{FEV}_{1}, \mathrm{~L} \text {, mean (SD) }\end{array}$ & $\begin{array}{l}17(11) \\
50.7(15.7) \\
1.247(0.429) \\
47.6(15.5) \\
1.171(0.419)\end{array}$ & $\begin{array}{l}8(5) \\
51.3(16.0) \\
1.287(0.435) \\
48.1(15.7) \\
1.207(0.424)\end{array}$ & $\begin{array}{l}\text { I (I) } \\
47.3(14.8) \\
1.140(0.384) \\
44.9(14.9) \\
1.086(0.395)\end{array}$ & $\begin{array}{l}734(18) \\
45.7(15.0) \\
1.275(0.488) \\
41.9(14.6) \\
1.170(0.468)\end{array}$ & $\begin{array}{l}810(20) \\
45.5(14.8) \\
1.272(0.486) \\
41.6(14.5) \\
1.163(0.468)\end{array}$ & $\begin{array}{l}366(18) \\
45.4(14.7) \\
1.268(0.481) \\
41.8(14.4) \\
1.167(0.464)\end{array}$ \\
\hline $\begin{array}{l}\text { GOLD grade, } \mathbf{n}(\%) \\
\text { I (mild: } \mathrm{FEV}, \% \text { predicted } \geq 80 \% \text { ) } \\
2 \text { (moderate: } 50 \% \leq \mathrm{FEV}, \% \text { predicted <80\%) } \\
3 \text { (severe: } 30 \% \leq \mathrm{FEV}, \% \text { predicted }<50 \% \text { ) } \\
4 \text { (very severe: } \mathrm{FEV}_{1} \% \text { predicted }<30 \% \text { ) }\end{array}$ & $\begin{array}{l}1(<1) \\
73(49) \\
60(40) \\
15(10)\end{array}$ & $\begin{array}{l}0 \\
65(44) \\
72(48) \\
12(8)\end{array}$ & $\begin{array}{l}0 \\
27(34) \\
43(54) \\
10(13)\end{array}$ & $\begin{array}{l}10(<1) \\
1535(37) \\
1934(47) \\
666(16)\end{array}$ & $\begin{array}{l}8(<1) \\
1455(35) \\
2031(49) \\
639(15)\end{array}$ & $\begin{array}{l}4(<1) \\
729(35) \\
1017(49) \\
319(15)\end{array}$ \\
\hline $\begin{array}{l}\text { CAT score, mean (SD) } \\
\text { SGRQ total score, mean (SD) }\end{array}$ & $\begin{array}{l}14.6(5.8) \\
39.6(14.2)\end{array}$ & $\begin{array}{l}14.9(7.3) \\
39.8(16.1)\end{array}$ & $\begin{array}{l}15.4(6.9) \\
42.8(15.4)\end{array}$ & $\begin{array}{l}18.2(7.0) \\
50.8(16.8)\end{array}$ & $\begin{array}{l}18.3(7.0) \\
50.7(17.0)\end{array}$ & $\begin{array}{l}18.1(6.9) \\
50.2(16.7)\end{array}$ \\
\hline $\begin{array}{l}\text { COPD medication, } \mathbf{n}(\%) \\
\text { ICS+LABA+LAMA } \\
\text { ICS+LABA } \\
\text { LABA+LAMA } \\
\text { LAMA }\end{array}$ & $\begin{array}{l}38(26) \\
16(11) \\
37(25) \\
24(16)\end{array}$ & $\begin{array}{l}39(26) \\
13(9) \\
31(21) \\
32(21)\end{array}$ & $\begin{array}{l}30(38) \\
7(9) \\
17(21) \\
9(11)\end{array}$ & $\begin{array}{l}1396(34) \\
1103(27) \\
330(8) \\
273(7)\end{array}$ & $\begin{array}{l}1433(35) \\
1067(26) \\
308(7) \\
331(8)\end{array}$ & $\begin{array}{l}734(35) \\
523(25) \\
163(8) \\
140(7)\end{array}$ \\
\hline History of pneumonia, n (\%) & $47(32)$ & $57(38)$ & $34(43)$ & $916(22)$ & $951(23)$ & $476(23)$ \\
\hline $\begin{array}{l}\text { Blood eosinophil count, } \mathbf{n} \text { (\%) } \\
\quad<150 \text { cells } / \mu \mathrm{L} \\
<300 \text { cells } / \mu \mathrm{L} \\
\geq 150 \text { cells } / \mu \mathrm{L} \\
\geq 300 \text { cells } / \mu \mathrm{L}\end{array}$ & $\begin{array}{l}76(51) \\
123(83) \\
73(49) \\
26(17)\end{array}$ & $\begin{array}{l}71(48) \\
124(83) \\
78(52) \\
25(17)\end{array}$ & $\begin{array}{l}38(48) \\
58(72) \\
42(52) \\
22(28)\end{array}$ & $\begin{array}{l}1844(45) \\
3280(79) \\
2299(55) \\
863(21)\end{array}$ & $\begin{array}{l}1769(43) \\
3212(78) \\
2356(57) \\
913(22)\end{array}$ & $\begin{array}{l}869(42) \\
1597(77) \\
1196(58) \\
468(23)\end{array}$ \\
\hline
\end{tabular}

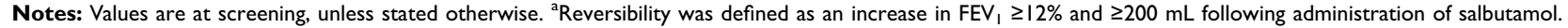
Abbreviations: BMI, body mass index; CAT, chronic obstructive pulmonary disease Assessment Test; ; FF, fluticasone furoate; ICS, inhaled corticosteroid; ITT, intent-totreat; LABA, long-acting $\beta_{2}$-adrenergic antagonist; LAMA, long-acting muscarinic antagonist; SGRQ, St. George's Respiratory Questionnaire; UMEC, umeclidinium; VI, vilanterol. 
proportion of all patients in the Japan subgroup had GOLD grade 2 status (Japan: 34-49\%; ITT: 35-37\%), were male (Japan: 90-94\%; ITT: 66-67\%), were older (mean age 70.1-71.1 years in Japan vs 65.2-65.3 years in ITT), had low BMI (Japan [mean]: 21.6-22.8 kg/m²; ITT: 26.6-26.7 $\mathrm{kg} / \mathrm{m}^{2}$ ), were on LABA+LAMA (Japan: $21-25 \%$; ITT: $7-$ $8 \%$ ) or LAMA monotherapy (Japan: $11-21 \%$; ITT: 7-8\%), and had a history of pneumonia (Japan: 32-43\%; ITT: 22 $23 \%$ ). The mean SGRQ total scores at baseline in each treatment arm were lower in the Japan cohort (39.6-42.8) than in the overall ITT population (50.2-50.8), as were CAT scores (Japan: 14.6-15.4; ITT: 18.1-18.3) (Table 1). A smaller proportion of patients had GOLD grade 4 status (Japan: 8-13\%; ITT: 15-16\%), were current smokers (Japan: 18-27\%; ITT: 34-35\%), were reversible to salbutamol (Japan: 1-11\%; ITT: 18-20\%), or were on ICS +LABA (Japan: 9-11\%; ITT: 25-27\%) or ICS+LABA +LAMA (Japan: 26-38\%; ITT: 34-35\%) in the Japan subgroup compared with the overall ITT population.

\section{Efficacy}

In the Japan subgroup, the annual rate ( $95 \% \mathrm{CI})$ of ontreatment moderate/severe exacerbations among patients randomized to FF/UMEC/VI was $0.90(0.71,1.15)$, compared with $1.07(0.83,1.37)$ among those randomized to FF/VI (15\% [95\% CI: $-20,40]$ rate reduction for $\mathrm{FF} /$ $\mathrm{UMEC} / \mathrm{VI}$ vs FF/VI) and $1.42(1.04,1.92)$ among those randomized to UMEC/VI $(36 \%$ [95\% CI: 6, 57] rate reduction for FF/UMEC/VI vs UMEC/VI). These findings were consistent with those in the ITT population in which the annual rate of moderate/severe exacerbations was significantly lower with FF/UMEC/VI versus either dual therapy $(\mathrm{p}<0.001)$ (Figure 1).

In the Japan subgroup, point estimates for the reduction in risk (time-to-first) of on-treatment moderate/severe exacerbations favored FF/UMEC/VI over both dual therapies, although CIs were wide, owing to the small patient population. $\mathrm{FF} /$ UMEC/VI showed a numerical reduction in moderate/severe exacerbation risk (time-to-first) by $13.5 \%$ (95\% CI: -23.8 , $39.5)$ versus $\mathrm{FF} / \mathrm{VI}$ and by $20.8 \%(95 \% \mathrm{CI}$ : $-18.9,47.2)$ versus UMEC/VI. These findings were consistent with those in the ITT population in which the risk (time-to-first) of on-treatment moderate/severe exacerbations was significantly lower with FF/UMEC/VI versus either dual therapy (both $\mathrm{p}<0.001$ ) (Figure 2).

Consistent with the ITT population, in the Japan subgroup, improvements in change from baseline in trough $\mathrm{FEV}_{1}$ and post-bronchodilator $\mathrm{FEV}_{1}$ at Week 52 were observed for $\mathrm{FF} / \mathrm{UMEC} / \mathrm{VI}$ versus FF/VI (treatment difference: $105 \mathrm{~mL}$; 95\% CI: 43, 167 and $109 \mathrm{~mL}$; 95\% CI: 50, 168, respectively) (Figure 3A and B). Numerical improvements were observed for change from baseline at Week 52 in trough $\mathrm{FEV}_{1}$ and post-bronchodilator $\mathrm{FEV}_{1}$ for $\mathrm{FF} /$ UMEC/VI versus UMEC/VI (treatment difference: $62 \mathrm{~mL}$; 95\% CI: $-12,137$ and $41 \mathrm{~mL}$; 95\% CI: -30 , 112, respectively) (Figure $3 \mathrm{~A}$ and $\mathrm{B}$ ).

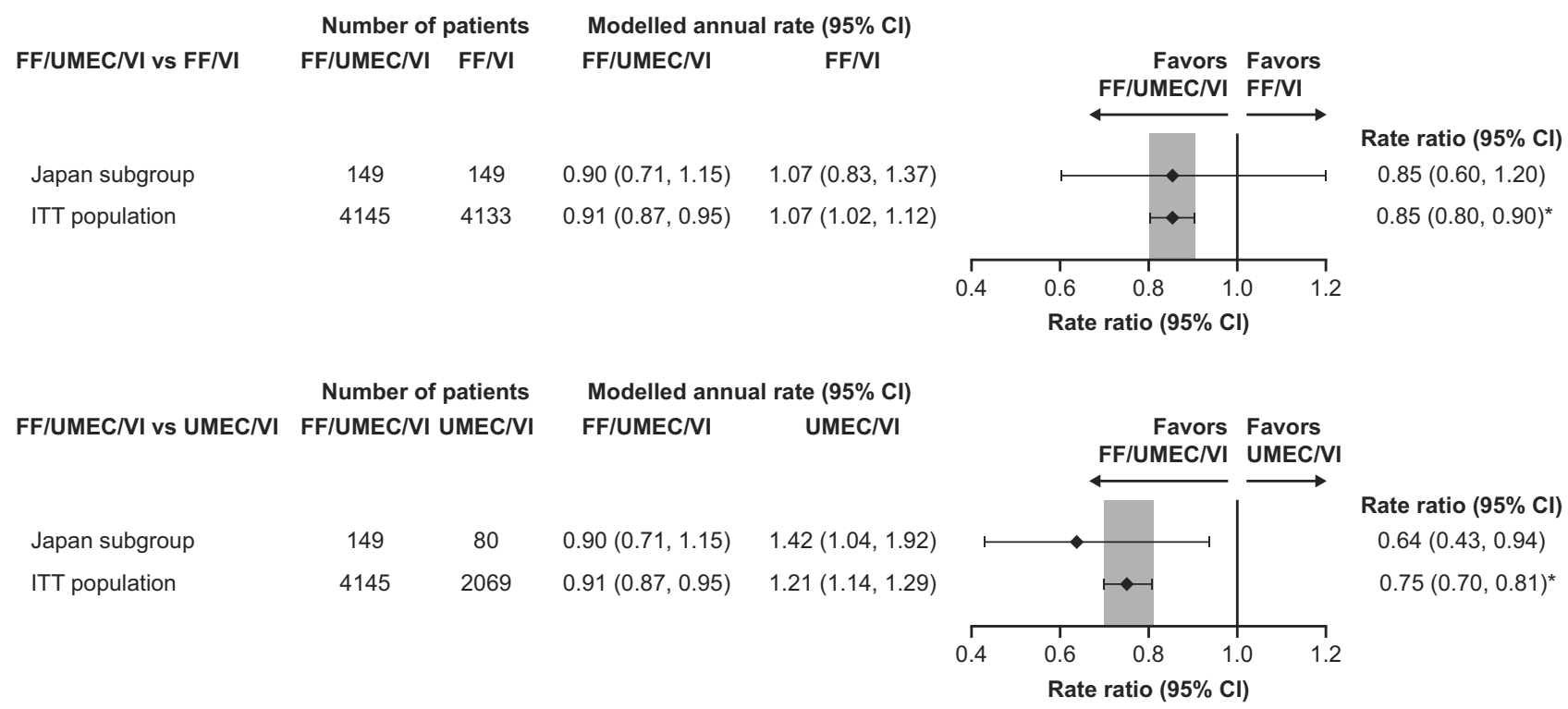

Figure I On-treatment moderate/severe exacerbations in the Japan subgroup and overall study population with FF/UMEC/VI versus dual therapies (ITT populations). Note: ${ }^{*} \mathrm{p}<0.001$.

Abbreviations: FF, fluticasone furoate; ITT, intent-to-treat; UMEC, umeclidinium; VI, vilanterol. 


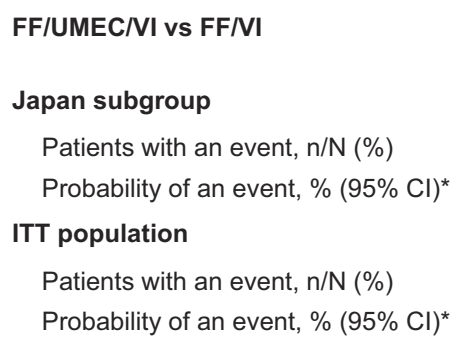

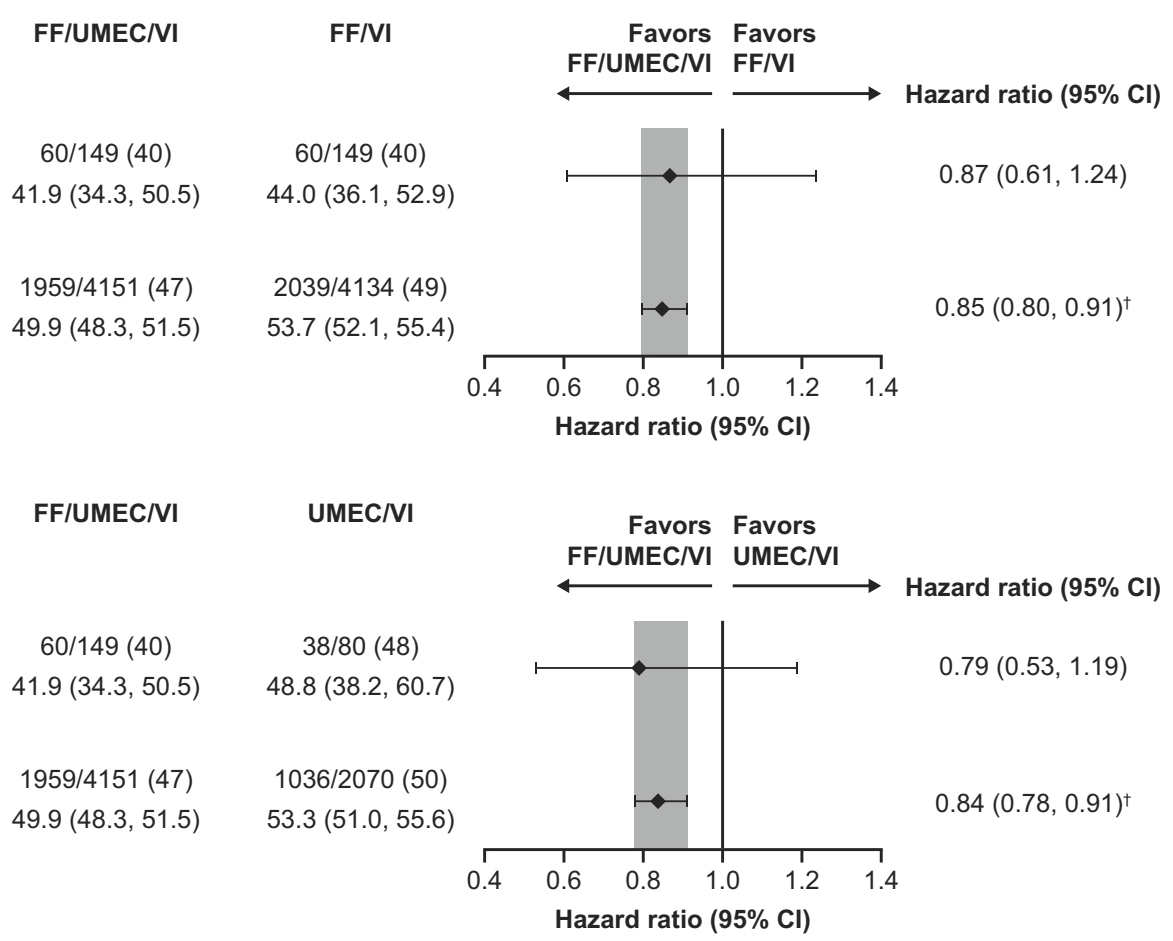

Figure 2 Time-to-first on-treatment moderate/severe exacerbation in the Japan subgroup and overall study population with FF/UMEC/VI versus dual therapies (ITT populations).

Notes: *Probability of having an event (prior to Day 365 ) is taken from the Kaplan-Meier estimates; ${ }^{\dagger} \mathrm{p}<0.001$. Abbreviations: FF, fluticasone furoate; ITT, intent-to-treat; UMEC, umeclidinium; VI, vilanterol.

At Week 52 in the Japan subgroup, all treatments demonstrated reductions from baseline (ie, improvements) in SGRQ total score. Numerical improvements in change from baseline in SGRQ total score were observed for FF/ UMEC/VI versus FF/VI (treatment difference -1.5 ; 95\% CI: $-4.9,1.9$ ) and $\mathrm{FF} / \mathrm{UMEC} / \mathrm{VI}$ versus UMEC/VI (treatment difference -0.9 ; 95\% CI: $-5.0,3.2$ ) (Figure 4A). At Week 52, all treatments also demonstrated reductions from baseline (ie, improvements) in CAT score in the Japan subgroup. In this subgroup, FF/UMEC/VI demonstrated a numerical improvement in the mean change from baseline in CAT score compared with both FF/VI (treatment difference -0.6 ; 95\% CI: $-2.1,1.0$ ) and UMEC/VI (treatment difference -1.5 ; 95\% CI: $-3.4,0.3$ ) (Figure 4B). These results are in line with those observed in the overall ITT population (Figure 4A and B).

\section{Safety Endpoints}

A similar incidence of on-treatment AEs, drug-related AEs, and SAEs were observed across all treatment arms, and no new safety signals were identified in patients from Japan relative to the overall ITT population (Table 2). In the Japan subgroup, the incidence of all broad and narrow definition MACE was $\leq 1 \%$ across all treatment arms (Supplementary Table 1).

Hypersensitivity AESI and lower respiratory tract infections excluding pneumonia AESI occurred at a higher incidence in the Japan subgroup compared with the ITT population; however, the incidence across treatment arms was similar (Table 2). No adrenal suppression, tremor, or urinary retention AESI were observed in the Japan cohort, consistent with the low incidence $(<1 \%)$ of these events in all treatment arms in the ITT population. ${ }^{13}$ All other AESI occurred at similar incidences to that in the ITT population, with the exception of pneumonia. As expected based on the class effect for ICS in patients with $\mathrm{COPD},{ }^{23}$ the incidence of pneumonia AESI was highest in ICS-containing treatment arms. The incidence of pneumonia AESI in these treatment arms was higher in Japan compared with the ITT population, with incidences of $18 \%, 21 \%$, and $5 \%$ for FF/UMEC/VI, FF/ VI, and UMEC/VI, respectively, in the Japan subgroup, compared with incidences of $8 \%, 7 \%$, and $5 \%$, respectively, in the ITT population (Table 2).

In the Japan subgroup, the incidence of adjudicated COPD exacerbation with evidence of pneumonia SAEs was consistent across treatment groups (Table 2). The incidence of these 


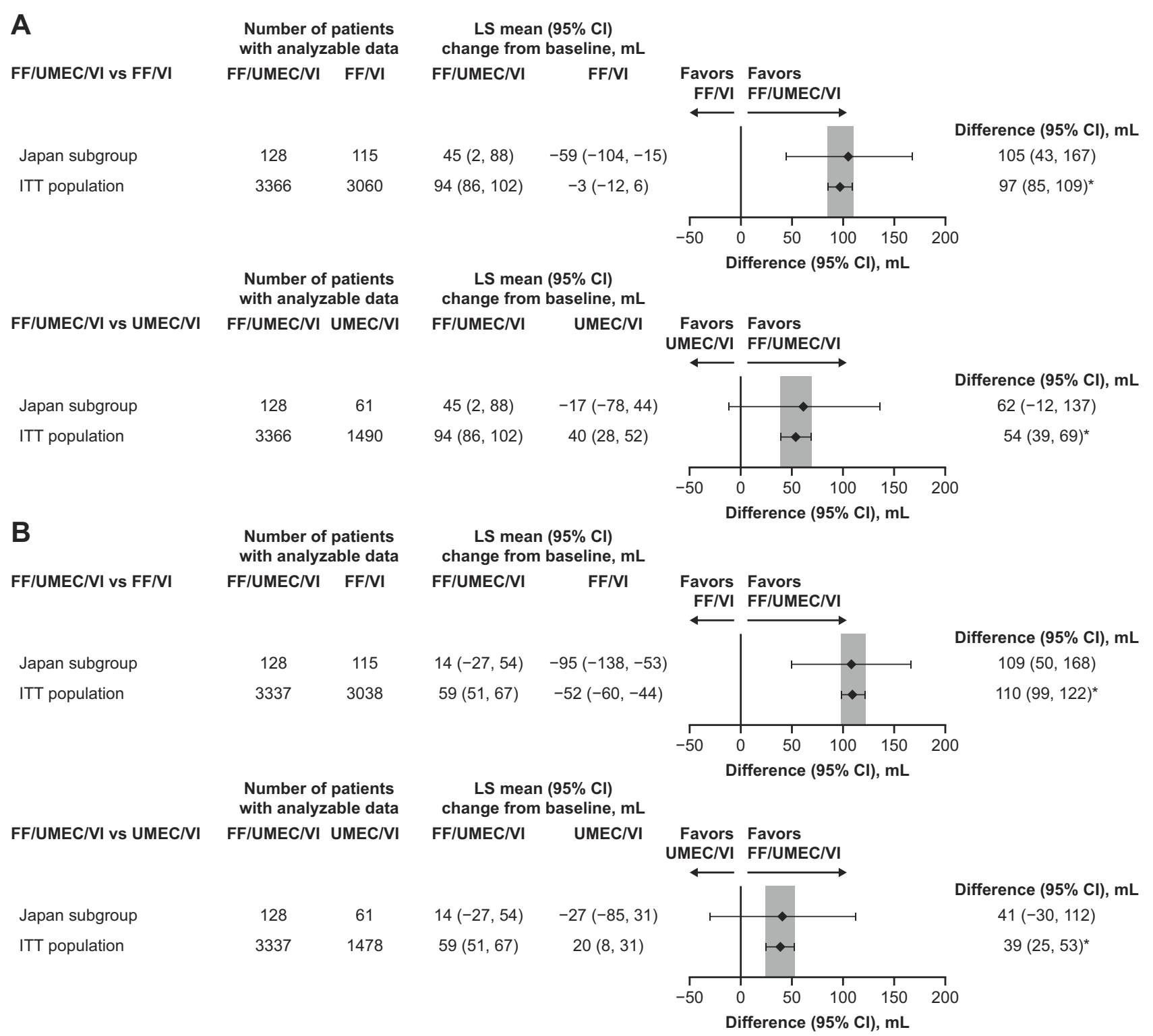

Figure 3 Change from baseline at Week 52 in (A) trough FEV , and (B) post-bronchodilator FEV , in the Japan subgroup and overall study population with FF/UMEC/VI versus dual therapies (ITT populations).

Note: $*_{\mathrm{p}}<0.001$.

Abbreviations: FF, fluticasone furoate; ITT, intent-to-treat; LS, least squares; UMEC, umeclidinium; VI, vilanterol.

events was slightly higher in all treatment arms in Japan (n [\%]: FF/UMEC/VI: 9 [6]; FF/VI: 8 [5]; UMEC/VI: 6 [8]) compared with the ITT population (n [\%]: FF/UMEC/VI: 123 [3]; FF/VI: 129 [3]; UMEC/VI: 57 [3]). In Japan, the incidence of adjudicated pneumonia/RTI without evidence of COPD exacerbation SAEs was higher in the ICS-containing treatment arms compared with the UMEC/VI arm (n [\%]: FF/UMEC/ VI: 7 [5]; FF/VI: 9 [6]; UMEC/VI: 0 [0]), unlike what was observed in the ITT population, where incidence of these events was consistent across treatment arms (n [\%]: FF/ UMEC/VI: 63 [2]; FF/VI: 59 [1]; UMEC/VI: 21 [1]).

\section{Discussion}

In the small subgroup of patients from the IMPACT study enrolled in Japan, FF/UMEC/VI single-inhaler triple therapy reduced the rate and risk (time-to-first) of moderate/ severe exacerbations, and improved lung function and health status versus dual therapy with either FF/VI or UMEC/VI. In this subgroup, comparisons of FF/UMEC/ VI to both dual therapies were consistently observed to be in the same direction as the results in the overall ITT population, indicating the consistency of benefits of triple therapy over dual therapy across multiple endpoints. 


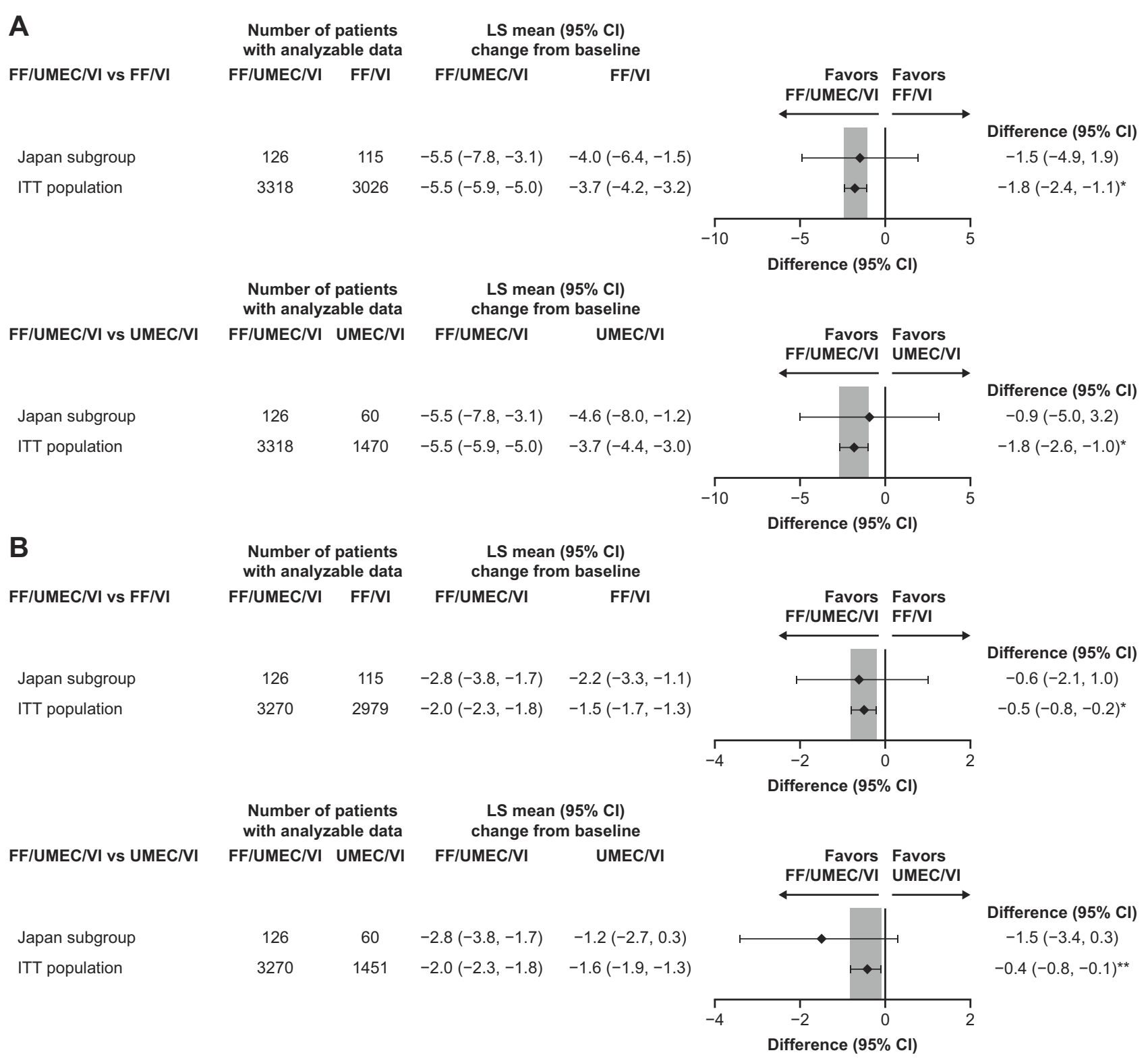

Figure 4 Change from baseline at Week 52 in (A) SGRQ total score and (B) CAT score in the Japan subgroup and overall study population with FF/UMEC/VI versus dual therapies (ITT populations).

Notes: ${ }^{*} \mathrm{p}<0.001 ; * * \mathrm{p}=0.021$.

Abbreviations: CAT, Chronic obstructive pulmonary disease Assessment Test; FF, fluticasone furoate; ITT, intention to treat; LS, least squares; SGRQ, St. George's Respiratory Questionnaire; UMEC, umeclidinium; VI, vilanterol.

The results in the Japan subgroup were also generally of a similar magnitude to those seen in the overall ITT population. However, it is interesting to note that in this subgroup of patients from IMPACT, which consisted of a greater proportion of patients with milder airflow limitation compared with the overall ITT population, the reduction in the rate of moderate/severe exacerbation for $\mathrm{FF} / \mathrm{UMEC} / \mathrm{VI}$ versus UMEC/VI was of a greater magnitude than that seen in the overall ITT population (point estimate: $36 \%$ vs $25 \%$ reduction, respectively). Similarly, improvements in CAT score with FF/UMEC/VI versus UMEC/VI were of a greater magnitude in the Japan subgroup compared with the ITT population, although in both cases the large CIs in the Japan subgroup are notable, reflecting the smaller patient numbers. The size of the Japan subgroup was relatively limited $(n=378)$ in the IMPACT study, which led to greater statistical variability in this subgroup compared with the overall ITT population.

Other studies have evaluated single-inhaler triple therapies versus dual or monotherapies in patients with COPD; 
Table 2 Safety Summary In Japan Subgroup And Overall Study Population (ITT populations)

\begin{tabular}{|c|c|c|c|c|c|c|}
\hline \multirow[t]{2}{*}{ AE incidence, $n(\%)$} & \multicolumn{3}{|l|}{ Japan } & \multicolumn{3}{|l|}{ Overall } \\
\hline & $\begin{array}{l}\text { FF/UMEC/VI } \\
n=149\end{array}$ & $\begin{array}{l}F F / V I \\
n=I 49\end{array}$ & $\begin{array}{l}\text { UMEC/VI } \\
n=80\end{array}$ & $\begin{array}{l}\text { FF/UMEC/VI } \\
n=4|5|\end{array}$ & $\begin{array}{l}\text { FF/VI } \\
n=4 I 34\end{array}$ & $\begin{array}{l}\text { UMEC/VI } \\
n=2070\end{array}$ \\
\hline $\begin{array}{l}\text { Any on-treatment } \mathbf{A E} \\
\text { Any on-treatment drug-related } \mathrm{AE}^{\mathrm{a}}\end{array}$ & $\begin{array}{l}117(79) \\
19(13)\end{array}$ & $\begin{array}{l}116(78) \\
19(13)\end{array}$ & $\begin{array}{l}61(76) \\
7(9)\end{array}$ & $\begin{array}{l}2897(70) \\
478(12)\end{array}$ & $\begin{array}{l}2800 \\
(68) \\
492(12)\end{array}$ & $\begin{array}{l}1429(69) \\
214(10)\end{array}$ \\
\hline $\begin{array}{l}\text { On-treatment AESI } \\
\text { Anticholinergic syndrome (SMQ) } \\
\text { Asthma/bronchospasm (SMQ) } \\
\text { Cardiovascular effects } \\
\text { Decreased BMD and associated fractures } \\
\text { Effects on potassium } \\
\text { Gastrointestinal obstruction (SMQ) } \\
\text { Hyperglycemia/new onset diabetes mellitus (SMQ) } \\
\text { Hypersensitivity } \\
\text { LRTI excluding pneumonia } \\
\text { Local steroid effects } \\
\text { Ocular effects } \\
\text { Pneumonia }\end{array}$ & $\begin{array}{l}8(5) \\
0(0) \\
10(7) \\
6(4) \\
1(<1) \\
0(0) \\
6(4) \\
13(9) \\
13(9) \\
15(10) \\
1(<1) \\
27(18)\end{array}$ & $\begin{array}{l}4(3) \\
0(0) \\
11(7) \\
2(1) \\
3(2) \\
1(<1) \\
4(3) \\
14(9) \\
12(8) \\
10(7) \\
3(2) \\
31(21)\end{array}$ & $\begin{array}{l}3(4) \\
2(3) \\
8(10) \\
1(1) \\
0(0) \\
0(0) \\
5(6) \\
9(11) \\
7(9) \\
6(8) \\
1(1) \\
4(5)\end{array}$ & $\begin{array}{l}184(4) \\
27(<1) \\
450(11) \\
98(2) \\
34(<1) \\
9(<1) \\
152(4) \\
196(5) \\
200(5) \\
337(8) \\
55(1) \\
317(8)\end{array}$ & $\begin{array}{l}140(3) \\
34(<1) \\
430(10) \\
85(2) \\
25(<1) \\
10(<1) \\
117(3) \\
195(5) \\
199(5) \\
301(7) \\
45(1) \\
292(7)\end{array}$ & $\begin{array}{l}70(3) \\
16(<1) \\
224(11) \\
37(2) \\
8(<1) \\
2(<1) \\
73(4) \\
95(5) \\
108(5) \\
108(5) \\
26(1) \\
97(5)\end{array}$ \\
\hline $\begin{array}{l}\text { Any on-treatment SAE } \\
\text { Any on-treatment drug-related } \mathrm{SAE}^{\mathrm{a}} \\
\text { Any on-treatment fatal } \mathrm{SAE}\end{array}$ & $\begin{array}{l}35(23) \\
4(3) \\
2(1)\end{array}$ & $\begin{array}{l}44(30) \\
6(4) \\
I(<1)\end{array}$ & $\begin{array}{l}17(21) \\
0(0) \\
0(0)\end{array}$ & $\begin{array}{l}895(22) \\
64(2) \\
68(2)\end{array}$ & $\begin{array}{l}850(2 I) \\
57(1) \\
76(2)\end{array}$ & $\begin{array}{l}470(23) \\
27(1) \\
49(2)\end{array}$ \\
\hline $\begin{array}{l}\text { On-treatment SAE occurring in }>1 \% \text { of patients } \\
\text { in any treatment arm } \\
\text { COPD } \\
\text { Pneumonia } \\
\text { Pneumonia bacterial } \\
\text { Cardiac failure congestive }\end{array}$ & $\begin{array}{l}15(10) \\
15(10) \\
1(<1) \\
0(0)\end{array}$ & $\begin{array}{l}18(12) \\
17(11) \\
4(3) \\
1(<1)\end{array}$ & $\begin{array}{l}10(13) \\
0(0) \\
0(0) \\
2(3)\end{array}$ & $\begin{array}{l}443(I I) \\
184(4) \\
2(<I) \\
21(<1)\end{array}$ & $\begin{array}{l}450(11) \\
152(4) \\
9(<1) \\
12(<1)\end{array}$ & $\begin{array}{l}269(13) \\
54(3) \\
0(0) \\
7(<1)\end{array}$ \\
\hline $\begin{array}{l}\text { Adjudicated on-treatment pneumonia-related } \\
\text { SAEs } \\
\text { COPD exacerbation with evidence of pneumonia } \\
\text { Pneumonia/RTI without COPD exacerbation }\end{array}$ & $\begin{array}{l}9(6) \\
7(5)\end{array}$ & $\begin{array}{l}8(5) \\
9(6)\end{array}$ & $\begin{array}{l}6(8) \\
0(0)\end{array}$ & $\begin{array}{l}123(3) \\
63(2)\end{array}$ & $\begin{array}{l}129(3) \\
59(1)\end{array}$ & $\begin{array}{l}57(3) \\
21(1)\end{array}$ \\
\hline
\end{tabular}

Notes: a In the opinion of the investigator; ${ }^{b}$ Adjudication performed by an independent adjudication committee (only the primary event in the SAE report was adjudicated). Abbreviations: AE, adverse event; BMD, bone mineral density; FF, fluticasone furoate; ITT, intent-to-treat; LRTI, lower respiratory tract infection; RTI, respiratory tract infection; SAE, serious adverse event; SMQ, Standardized MedDRA (Medical Dictionary for Regulatory Activities) query; UMEC, umeclidinium; VI, vilanterol.

however, design differences limit the comparisons that can be made with the IMPACT study results. The TRIBUTE $(\mathrm{NCT} 02579850)^{21}$ and TRINITY (NCT01911364) ${ }^{24}$ studies did not include study sites in Asia and recruited a lower proportion of patients with a history of frequent or severe exacerbations, as indicated by the proportion of GOLD D patients (IMPACT: 70\%; TRIBUTE: 37\%; TRINITY: 51\%), limiting comparisons with this analysis. ${ }^{13,25,26}$ The KRONOS study (NCT02497001) did include patients from Japan and efficacy and safety results in this patient subgroup have been recently presented. ${ }^{27,28}$ However, this study included patients at lower risk of exacerbation than patients in the IMPACT study, as indicated by the fact that the majority (74\%) of the KRONOS population had no moderate/severe exacerbations in the year prior to study entry. ${ }^{29}$ In the Japan subgroup of the KRONOS study, improvements in lung function and symptoms were seen over Weeks 12-24 with budesonide/glycopyrrolate/formoterol fumarate (BGF) triple therapy versus LAMA/LABA (glycopyrrolate/formoterol fumarate $[\mathrm{GFF}]$ ) or ICS/LABA (budesonide/formoterol fumarate $[\mathrm{BFF}]$ ) dual therapy, and a reduction in annual exacerbation rates with BGF triple therapy versus GFF dual therapy was observed. ${ }^{28}$ These results from the KRONOS study provide further evidence for the use of single-inhaler triple therapy in Japan. 
Studies have highlighted the effect of COPD on patients' HRQoL and the associated economic burden of COPD in Japan. ${ }^{30}$ The results from this subgroup analysis of the IMPACT study indicate that use of FF/UMEC/VI single-inhaler triple therapy could provide improvements in health status in patients with symptomatic COPD and at least one moderate/severe exacerbation in the previous year, compared with dual bronchodilator or ICS/LABA therapy. At Week 52, improvements in both SGRQ total score and CAT score were observed with FF/UMEC/VI versus both dual therapies. It is worth noting that improvements in CAT score with FF/UMEC/VI versus UMEC/VI were of a greater magnitude in the Japan subgroup compared with the ITT population, although small patient numbers limit result interpretation.

No new safety signals were identified in the Japan subgroup. However, there was a higher incidence of both pre-study and on-treatment documented pneumonia in the Japan subgroup compared with the overall ITT population, as has been noted in previous studies in Asia. ${ }^{31,32}$ This may in part be due to differences in pneumonia reporting. Interestingly, the higher reporting of pneumonia usually seen in Japan was not observed in the UMEC/VI arm. This is in contrast to the subgroup analysis of the DYNAGITO (NCT02296138) study in Japan, which showed higher incidence of pneumonia in both the tiotropium and tiotropium/olodaterol treatment arms in the Japan cohort (14\% and $15 \%$, respectively) compared with the overall ITT population (5\% in both arms). ${ }^{33,34}$

A previous post hoc analysis identified potential risk factors for pneumonia including older age ( $>65$ years), lower $\%$ predicted $\mathrm{FEV}_{1}(<30 \%$ predicted), exacerbations in the previous year, and lower BMI. ${ }^{35}$ Therefore, in this analysis of IMPACT study data, patients in the Japan subgroup may have been at greater risk of developing pneumonia as the majority were $\geq 65$ years of age, had lower BMIs, and a higher incidence of pre-study pneumonia compared with the overall population.

A difference in pneumonia incidence between the ITT population and the Japan subgroup was also observed in the subgroup analysis of the KRONOS study. ${ }^{27-29}$ In the ITT population of the KRONOS study, the incidence of adjudicated pneumonia events over 24 weeks was low and similar between treatment groups (BGF: 1.9\%, GFF: $1.6 \%$, BFF: $1.9 \%$ ), while the incidence of documented events was slightly higher in ICS-containing treatment arms compared with the GFF arm (BGF: 2.5\%, GFF: $1.8 \%$, BFF: $2.2 \%){ }^{29}$ In the KRONOS Japan subgroup, the incidence of adjudicated and clinician-diagnosed pneumonia over 24 weeks was higher in the triple therapy arm than in the dual therapy arms (adjudicated: BGF $5.0 \%$, GFF $0.7 \%$, BFF $0.0 \%$; clinician-diagnosed: BGF $4.3 \%$, GFF $0.7 \%$, BFF $1.4 \%) .{ }^{28}$ In the 28 -week extension phase of the KRONOS study in Japan, the incidence of pneumonia over 52 weeks of treatment was higher in ICS-containing arms compared with the GFF arm (adjudicated: BGF 9.4\%, GFF 3.6\%, BFF 5.7\%; clinician-diagnosed: BGF $10.1 \%$, GFF $3.6 \%$, BFF 5.7\%). ${ }^{27}$ Further analyses indicated that the difference in adjudicated pneumonia incidence between triple therapy and dual therapies was most pronounced in the first 24 weeks. ${ }^{27}$ This is similar to what was observed in the FULFIL study (NCT02345161), in which the incidence of pneumonia was higher with $\mathrm{FF} /$ UMEC/VI than with budesonide/formoterol in the first 24 weeks, but similar between the two treatment arms at 52 weeks. ${ }^{36}$ These differences between ITT and Japan subgroups in the IMPACT and KRONOS study may reflect variability due to lower patient numbers.

When considering only the adjudicated SAEs in the IMPACT Japan subgroup, the incidence of adjudicated COPD exacerbation with evidence of pneumonia SAEs was consistent across treatment groups. This is in line with overall ITT results, although the incidence was higher in all treatment arms in Japan. In the IMPACT Japan cohort, the incidence of adjudicated pneumonia/RTI without evidence of COPD exacerbation SAEs was higher in the ICS-containing treatment arms compared with the $\mathrm{UMEC} / \mathrm{VI}$ arm, unlike in the ITT population where incidence was similar across all treatment arms. When considering the overall incidence of adjudicated pneumonia SAEs (COPD exacerbation with evidence of pneumonia and pneumonia/RTI without evidence of COPD exacerbation combined), these events occurred with a similar incidence across all treatment arms in Japan, in line with ITT results, although the incidence was higher in all treatment arms in Japan. The overall ITT results therefore reflect what was observed in the TRINITY and TRIBUTE studies, ${ }^{21,24}$ and further investigation into the reasons underlying the increased incidence of pneumonia in the IMPACT Japan subgroup are warranted. Possible reasons include the higher presence of risk factors for pneumonia in the Japan subgroup, as mentioned above (ie, older age, lower BMI, history of pneumonia). Another possible reason is that Japanese physicians often order computed tomography scans, ${ }^{37,38}$ which help to identify pneumonia that may otherwise go undiagnosed. 
The IMPACT study results in Japan highlight the favorable benefit-risk profile of FF/UMEC/VI single-inhaler triple therapy in patients with symptomatic COPD and at least 1 moderate/severe exacerbation in the previous year in Japan. These results are consistent with the overall study population, ${ }^{13}$ and with other studies of single- or multiple inhaler triple therapy. ${ }^{22}$

Some limitations should be considered when interpreting the results. First, the IMPACT Japan subgroup represents only $4 \%$ of the overall study population and, although a sizable number of patients from Japan $(n=378)$ were included in this global study, the limited sample size means that this sub-analysis was not powered to demonstrate statistically significant differences for any endpoint. In addition, differences in the treatment and management of COPD between Japan and the overall ITT population may explain some of the differences observed, particularly in terms of pneumonia incidence. A strength of this study is that it is the first in patients with COPD and a history of exacerbations in Japan demonstrating a favorable benefit-risk profile for single-inhaler triple therapy, and results in this subgroup were consistent with those in the overall IMPACT study population.

\section{Conclusion}

The results from this analysis highlight the favorable benefit-risk profile of FF/UMEC/VI single-inhaler triple therapy compared with FF/VI or UMEC/VI dual therapies in patients in Japan with symptomatic COPD and $\geq 1$ moderate/severe exacerbation in the previous year. FF/UMEC/VI therapy resulted in lower rates of moderate/severe exacerbations and improvements in lung function and health status compared with FF/VI and UMEC/VI in the Japan cohort, and results were in the same direction and generally of a similar magnitude to the overall study population, with no new safety signals identified.

\section{Ethics Approval And Informed Consent}

The study was conducted in accordance with Good Clinical Practice (GCP) guidelines and the provisions of the Declaration of Helsinki. All patients enrolled in IMPACT provided written informed consent. The study protocol, any amendments, the informed consent, and other information that required preapproval were reviewed and approved by national, regional, or investigational site ethics committees or institutional review boards, in accordance with the International
Council for Harmonisation of Technical Requirements for Registration of Pharmaceuticals for Human Use GCP and applicable for country-specific requirements, including US 21 Code of Federal Regulations 312.3(b) for constitution of independent ethics committees.

\section{Abbreviations}

AE, adverse event; AESI, adverse event of special interest; BFF, budesonide/formoterol fumarate; BGF, budesonide/ glycopyrrolate/formoterol fumarate; BMI, body mass index; CAT, COPD Assessment Test; FF, fluticasone furoate; GFF, glycopyrrolate/formoterol fumarate; HRQoL, healthrelated quality of life; ICS, inhaled corticosteroid; IMPACT, InforMing the PAthway of COPD Treatment; ITT, intent-to-treat; LABA, long-acting $\beta_{2}$-agonist; LAMA, long-acting muscarinic antagonist; MACE, major adverse cardiovascular events; RTI, respiratory tract infection; SAE, serious adverse event; SGRQ, St. George's Respiratory Questionnaire; UMEC, umeclidinium; VI, vilanterol.

\section{Data Availability}

Anonymized individual participant data and study documents can be requested for further research from www. clinicalstudydatarequest.com.

\section{Acknowledgments}

Editorial support (in the form of writing assistance, assembling figures, collating author comments, grammatical editing, and referencing) was provided by Chrystelle Rasamison and Hayley Mukherjee, PhD, at Fishawack Indicia Ltd, UK, and was funded by GSK. We thank the patients, families, and investigators in Japan who participated in the IMPACT trial. These data were presented in part at the 59th Annual Meeting of the Japanese Respiratory Society, Tokyo, Japan, 12 April 2019.

\section{Author contributions}

All authors meet criteria for authorship as recommended by the International Committee of Medical Journal Editors, take responsibility for the integrity of the work as a whole, contributed to the writing and reviewing of the manuscript, and have given final approval for the version to be published. All authors had full access to the data in this study, take complete responsibility for the integrity of the data and accuracy of the data analysis and agree to be accountable for all aspects of the work. $\mathrm{M}$ Kato and $\mathrm{K}$ Tomii contributed to the acquisition of data, K Hashimoto, Y Nezu, T Ishii, CE Jones, S Kilbride, A 
Gross, and C Clifton contributed to the data analysis and interpretation, DA Lipson contributed to the conception and design of the study, and to the data analysis and interpretation.

\section{Funding}

This study was funded by GlaxoSmithKline (GSK study number CTT116855; NCT02164513). The funders of the study had a role in the study design, data analysis, data interpretation, and writing of the report. Editorial support (in the form of writing assistance, assembling figures, collating author comments, grammatical editing, and referencing) was provided by Chrystelle Rasamison and Hayley Mukherjee, PhD, at Fishawack Indicia Ltd, UK, and was funded by GSK.

\section{Disclosure}

Motokazu Kato has received lecture honoraria from GSK, AstraZeneca, Nippon Boehringer Ingelheim, and Novartis Pharma. Keisuke Tomii has received lecture honoraria from Nippon Boehringer Ingelheim, AstraZeneca, GSK, Novartis Pharma, and Teijin Pharma. Kenichi Hashimoto, Takeo Ishii, C. Elaine Jones, Sally Kilbride, Annette S. Gross, Christine S. Clifton, and David A. Lipson are GSK employees and hold stock/shares in GSK. Yasuko Nezu is an employee of GSK. Ellipta is owned by or licensed to the GSK Group of Companies. The authors report no other conflicts of interest in this work.

\section{References}

1. Global Initiative for Chronic Obstructive Lung Disease. Global strategy for the diagnosis, management, and prevention of chronic obstructive pulmonary disease - 2019 report. 2019. Available from: https:// goldcopd.org. Accessed May 2019.

2. GBD 2017 Causes of Death Collaborators. Global, regional, and national age-sex-specific mortality for 282 causes of death in 195 countries and territories, 1980-2017: a systematic analysis for the Global Burden of Disease Study 2017. Lancet. 2018;392(10159):1736-1788.

3. GBD 2017 DALYs and Hale Collaborators. Global, regional, and national disability-adjusted life-years (DALYs) for 359 diseases and injuries and healthy life expectancy (HALE) for 195 countries and territories, 19902017: a systematic analysis for the Global Burden of Disease Study 2017. Lancet. 2018;392(10159):1859-1922.

4. Foreman KJ, Marquez N, Dolgert A, et al. Forecasting life expectancy, years of life lost, and all-cause and cause-specific mortality for 250 causes of death: reference and alternative scenarios for 2016-40 for 195 countries and territories. Lancet. 2018;392(10159):2052-2090. doi:10.1016/S0140-6736(18)31694-5

5. Ko FW, Hui DS, Lai CK. Worldwide burden of COPD in high- and low-income countries. Part III. Asia-Pacific studies. Int J Tuberc Lung Dis. 2008;12(7):713-717.

6. Igarashi A, Fukuchi Y, Hirata K, et al. COPD uncovered: a cross-sectional study to assess the socioeconomic burden of COPD in Japan. Int J Chron Obstruct Pulmon Dis. 2018;13:2629-2641. doi:10.2147/COPD
7. Zhong N, Moon HS, Lee KH, et al. TIOtropium safety and performance in respimat((R)) (TIOSPIR(TM)): analysis of Asian cohort of COPD patients. Respirology (Carlton, Vic). 2016;21(8):1397-1403. doi:10.1111/resp. 12856

8. Landis SH, Muellerova H, Mannino DM, et al. Continuing to confront COPD International Patient Survey: methods, COPD prevalence, and disease burden in 2012-2013. Int $J$ Chron Obstruct Pulmon Dis. 2014;9:597-611. doi:10.2147/COPD.S61854

9. Ishii T, Nishimura M, Akimoto A, James MH, Jones P. Understanding low COPD exacerbation rates in Japan: a review and comparison with other countries. Int J Chron Obstruct Pulmon Dis. 2018;13:3459-3471. doi: $10.2147 / \mathrm{COPD}$

10. Suzuki M, Makita H, Ito YM, Nagai K, Konno S, Nishimura M. Clinical features and determinants of COPD exacerbation in the Hokkaido COPD cohort study. Eur Respir J. 2014;43(5):12891297. doi:10.1183/09031936.00110213

11. The Committee for the Fifth Edition of the COPD Guidelines of The Japanese Respiratory Society. Guidelines for the Diagnosis and Treatment of COPD (Chronic Obstructive Pulmonary Disease). 5th ed. Pocket Guide; 2018 Available from: http://www.jrs.or.jp/modules/ guidelines/index.php?content_id=1. Accessed May 2019.

12. The Committee for the Fourth Edition of the COPD Guidelines of The Japanese Respiratory Society. Guidelines for the Diagnosis and Treatment of COPD (Chronic Obstructive Pulmonary Disease). 4th ed. Pocket Guide; 2013 Available from: http://www.jrs.or.jp/modules/ guidelines/index.php?content_id=1. Accessed May 2019.

13. Lipson DA, Barnhart F, Brealey N, et al. Once-daily single-inhaler triple versus dual therapy in patients with COPD. $N$ Engl J Med. 2018;378(18):1671-1680. doi:10.1056/NEJMoa1713901

14. Highlights of prescribing information - ANORO ELLIPTA. Available from: https://www.accessdata.fda.gov/drugsatfda_docs/label/2013/ 203975s000lbl.pdf. Accessed May 07, 2019.

15. Highlights of prescribing information - BREO ELLIPTA. Available from: https://www.accessdata.fda.gov/drugsatfda_docs/label/2017/ 204275s012lbl.pdf. Accessed May 07, 2019.

16. GlaxoSmithKline. Anoro ${ }^{\circledR}$ Ellipta ${ }^{\circledR}$ Japan Prescribing Information. Available from: https://www.pmda.go.jp/PmdaSearch/iyakuDetail/ ResultDataSetPDF/340278_2259806G1021_1_06. Accessed May 29, 2019.

17. GlaxoSmithKline. Relvar ${ }^{\circledR}$ Ellipta ${ }^{\circledR}$ Japan Prescribing Information. Available from: https://www.pmda.go.jp/PmdaSearch/iyakuDetail/ ResultDataSetPDF/340278_2290803G1028_1_09. Accessed May 29, 2019.

18. Pascoe SJ, Lipson DA, Locantore N, et al. A phase III randomised controlled trial of single-dose triple therapy in COPD: the IMPACT protocol. Eur Respir J. 2016;48(2):320-330. doi:10.1183/13993003. 02165-2015

19. Celli BR, MacNee W, Force AET. Standards for the diagnosis and treatment of patients with COPD: a summary of the ATS/ERS position paper. Eur Respir J. 2004;23(6):932-946. doi:10.1183/0903 1936.04.00014304

20. Asamoah-Boaheng M, Acheampong L, Tenkorang EY, Farrell J, Oyet A, Midodzi WK. Association between early history of asthma and COPD diagnosis in later life: a systematic review and meta-analysis. Int $J$ Epidemiol. 2018;47(6):1865-1876. doi:10.1093/ije/dyy207

21. Papi A, Vestbo J, Fabbri L, et al. Extrafine inhaled triple therapy versus dual bronchodilator therapy in chronic obstructive pulmonary disease (TRIBUTE): a double-blind, parallel group, randomised controlled trial. Lancet. 2018;391(10125):1076-1084. doi:10.1016/ S0140-6736(18)30206-X

22. Vanfleteren L, Fabbri LM, Papi A, Petruzzelli S, Celli B. Triple therapy (ICS/LABA/LAMA) in COPD: time for a reappraisal. Int $J$ Chron Obstruct Pulmon Dis. 2018;13:3971-3981. doi:10.2147/ COPD 
23. Tashkin DP, Strange C. Inhaled corticosteroids for chronic obstructive pulmonary disease: what is their role in therapy? Int J Chron Obstruct Pulmon Dis. 2018;13:2587-2601. doi:10.2147/COPD

24. Vestbo J, Papi A, Corradi M, et al. Single inhaler extrafine triple therapy versus long-acting muscarinic antagonist therapy for chronic obstructive pulmonary disease (TRINITY): a double-blind, parallel group, randomised controlled trial. Lancet. 2017;389(10082):19191929. doi:10.1016/S0140-6736(17)30188-5

25. Scuri M, Singh D, Fabbri L, et al. Single inhaler extrafine triple therapy improves clinical outcomes in GOLD B COPD patients: post-hoc analysis of the TRIBUTE study. Am J Respir Crit Care Med. 2018;197:A3041.

26. Singh D, Fabbri L, Papi A, et al. Extrafine triple therapy reduces exacerbations in GOLD B COPD patients: post-hoc analysis of TRILOGY and TRINITY. Eur Respir J. 2017;50(Suppl. 61): OA2898. doi:10.1183/13993003.00711-2017

27. Ichinose M, Fukushima Y, Inoue Y, et al. Long-term safety and tolerability of budesonide/glycopyronium/formoterol fumarate metered dose nebulizer (BGF MDI) using co-suspension technique in Japanese patients with chronic obstructive pulmonary disease (COPD). Paper presented at: Japanese Respiratory Society - 59th Annual Meeting 2019; Tokyo, Japan. (Poster PP280).

28. Ichinose M, Yasuyuki F, Inoue Y, et al. Efficacy and safety of budesonide/glycopyronium/formoterol fumarate metered dose nebulizer (BGF MDI) using co-suspension technique in Japanese patients with chronic obstructive pulmonary disease (COPD). Paper presented at: Japanese Respiratory Society - 59th Annual Meeting 2019; Tokyo, Japan. (Poster PP279).

29. Ferguson GT, Rabe KF, Martinez FJ, et al. Triple therapy with budesonide/glycopyrrolate/formoterol fumarate with co-suspension delivery technology versus dual therapies in chronic obstructive pulmonary disease (KRONOS): a double-blind, parallel-group, multicentre, phase 3 randomised controlled trial. Lancet Respir Med. 2018;6(10):747-758. doi:10.1016/S2213-2600(18)30327-8

30. Small M, Holbrook T, Wood R, Mullerova H, Naya I, Punekar YS. Prevalence and burden of dyspnoea among COPD patients in Japan. Int J Clin Pract. 2016;70(8):676-681. doi:10.1111/ijcp.2016.70.issue-8
31. Zheng J, Zhong N, Wang C, et al. The efficacy and safety of oncedaily fluticasone furoate/umeclidinium/vilanterol versus twice-daily budesonide/formoterol in a subgroup of patients from china with symptomatic COPD at risk of exacerbations (FULFIL trial). Copd. 2018;15(4):334-340. doi:10.1080/15412555.2018.1481022

32. Wedzicha JA, Zhong N, Ichinose M, et al. Indacaterol/glycopyrronium versus salmeterol/fluticasone in Asian patients with COPD at a high risk of exacerbations: results from the FLAME study. Int J Chron Obstruct Pulmon Dis. 2017;12:339-349. doi:10.2147/COPD

33. Calverley PMA, Anzueto AR, Carter K, et al. Tiotropium and olodaterol in the prevention of chronic obstructive pulmonary disease exacerbations (DYNAGITO): a double-blind, randomised, parallelgroup, active-controlled trial. Lancet Respir Med. 2018;6(5):337344. doi:10.1016/S2213-2600(18)30102-4

34. Ichinose M, Nishimura M, Akimoto M, et al. Tiotropium/olodaterol versus tiotropium in Japanese patients with COPD: results from the DYNAGITO study. Int J Chron Obstruct Pulmon Dis. 2018;13:21472156. doi:10.2147/COPD.S169941

35. Crim C, Calverley PM, Anderson JA, et al. Pneumonia risk in COPD patients receiving inhaled corticosteroids alone or in combination: TORCH study results. Eur Respir J. 2009;34(3):641-647. doi:10.11 83/09031936.00193908

36. Lipson DA, Barnacle H, Birk R, et al. FULFIL trial: once-daily triple therapy for patients with chronic obstructive pulmonary disease. Am J Respir Crit Care Med. 2017;196(4):438-446. doi:10.1164/rccm.201 703-0449OC

37. Brenner DJ. Minimising medically unwarranted computed tomography scans. Ann ICRP. 2012;41(3-4):161-169. doi:10.1016/j.icrp. 2012.06.004

38. Kumamaru KK, Machitori A, Koba R, Ijichi S, Nakajima Y, Aoki S. Global and Japanese regional variations in radiologist potential workload for computed tomography and magnetic resonance imaging examinations. Jpn J Radiol. 2018;36(4):273-281. doi:10.1007/ s11604-018-0724-5

\section{Publish your work in this journal}

The International Journal of COPD is an international, peer-reviewed journal of therapeutics and pharmacology focusing on concise rapid reporting of clinical studies and reviews in COPD. Special focus is given to the pathophysiological processes underlying the disease, intervention programs, patient focused education, and self management protocols. This journal is indexed on PubMed Central, MedLine and CAS. The manuscript management system is completely online and includes a very quick and fair peer-review system, which is all easy to use. Visit http://www.dovepress.com/testimonials.php to read real quotes from published authors. 